\title{
Compliance With the Surviving Sepsis Campaign Bundle: A Multicenter Study From Turkey
}

İlhan Bahar ${ }^{1}$, Hafize Oksuz ${ }^{2}$, Nimet Şenoğlu ${ }^{3}$, Hilmi Demirkiran ${ }^{4}$, Mustafa Aydoğan ${ }^{5}$, Yakup Tomak ${ }^{6}$, Mehmet Çömez ${ }^{7}$, Sinem Bayrakçı ${ }^{8}$, Edip Gönüllü̈ ${ }^{9}$, Mustafa Berktaş ${ }^{10}$

1. Anesthesiology and Reanimation, Bakırçay University Çiğli Training and Research Hospital, Izmir, TUR 2. Anesthesiology and Reanimation, Kahramanmaraş Sütçü imam University Faculty of Medicine, Kahramanmaraş, TUR 3. Anesthesia and Critical Care, Tepecik Training and Research Hospital, Izmir, TUR 4. Anesthesiology and Reanimation, University of Van Yuzuncu Yil, Van, TUR 5. Anesthesia and Critical Care, İnönü University Turgut Özal Medical Center, Malatya, TUR 6. Anesthesiology and Reanimation, Sakarya University Faculty of Medicine, Sakarya, TUR 7. Anesthesiology and Reanimation, Mustafa Kemal University Faculty of Medicine, Hatay, TUR 8. Anesthesiology and Reanimation, Ersin Aslan Training and Research Hospital, Gaziantep, TUR 9. Anesthesiology and Reanimation, University of Bakırçay, Izmir, TUR 10. Microbiology, Bakırçay University Faculty of Medicine, Izmir, TUR

Corresponding author: İlhan Bahar, mdilhanbahar@gmail.com

\section{Abstract \\ Objectives}

Sepsis bundle compliance is not clear. We evaluated rates of compliance with sepsis bundle protocols among health care providers in Turkey.

\section{Methods}

Our study was carried out retrospectively. Forty-five intensive care units (ICU) participated in this study between March 2, 2018 and October 1, 2018.

\section{Results}

One hundred thirty-eight ICUs were contacted and 45 ICUs agreed to participate. The time taken for the diagnosis of sepsis was less than six hours in 384 (59.8\%) patients, while it was more than six hours in 258 (40.2\%) patients. The median [interquartile range (IQR)] times for initial antibiotic administration, culturing, vasopressor initiation, and second lactate measurement were 120.0 (60-300) minutes, 24 (12-240) minutes, 40 (20-60) minutes, and 24 (18-24) hours, respectively. The rate of compliance with tissue and organ perfusion follow-up in the first six hours was $0 \%$. The rates of three- and six-hour sepsis bundle protocol compliance were both $0 \%$. The ICU mortality rates for sepsis and septic shock were $22 \%$ and $78 \%$, respectively. The ICU mortality rates for sepsis and septic shock were $22 \%$ and $78 \%$, respectively.

\section{Conclusions}

Review began 04/20/2021 Review ended 04/29/2021 Published 05/12/2021

\section{(๑) Copyright 2021}

Bahar et al. This is an open access article distributed under the terms of the Creative Commons Attribution License CC-BY 4.0., which permits unrestricted use, distribution, and reproduction in any medium, provided the original author and source are credited.
The rate of compliance with sepsis bundle protocols was evaluated in Turkey for the first time and determined to be $0 \%$.

Categories: Anesthesiology, Internal Medicine, Infectious Disease

Keywords: bundle, compliance, turkey, sepsis, guideline

\section{Introduction}

Sepsis is one of the most common disorders that causes mortality in intensive care units (ICUs) [1]. For the global management of sepsis, international guidelines from the Surviving Sepsis Campaign (SSC) have been published [2]. In 2018, the three- and six-hour bundles were reduced to one hour each by the SSC [3]. Prior observational studies have suggested that the mortality rate and costs of care can be reduced with greater bundle protocol compliance $[4,5]$. To improve bundle protocol compliance, specific training and infrastructure are necessary [6]; however, according to data from the World Health Organization, the ICUs in 83 countries do not meet minimum standards [7]. The most important reason among those known for ICUs failing to meet standards in this manner is the unavailability of adequate financial support. As compared with developed countries, developing ones typically spend less money and the number of nurses working in these countries is lower [8]; indeed, the number of nurses working in ICUs and the availability of equipment for bronchoscopy, ultrasonography, and hemodynamic monitoring in developing countries are often insufficient to meet patient needs [9]. Moreover, the number of patients per health care professional is high, and the number of beds is limited. Sanitation, electrical resources, ventilation, and patient safety are also often insufficient in hospitals in developing countries [10]. For example, in emergency services, levels of plasma lactate and other biomarkers cannot be measured [11]. Overall, the mortality rate is higher in developing countries [12]. Considering sepsis treatment specifically, according to World Bank data, Turkey is an upper-middle-income country [13]. In developed countries, compatibility with sepsis bundle is high and 
mortality is low [14]. Sepsis bundle compliance is mandatory in New York [15]. In a previous study conducted in our country, mortality of septic shock was found to be very high [16]. In our country, there is no multicenter study on bundle compliance, which is a mortality-reducing treatment. Our intention was therefore to determine the degree of sepsis bundle protocol compliance in Turkey.

\section{Materials And Methods \\ Design and setting}

Our study was carried out retrospectively. Every eligible medical center was contacted by phone about participating in this study, and the study protocol was sent to them by email. The study protocol is available at https://forms.gle/GRuqdXyAErt2Vmwz5. In total, 138 intensive care units were contacted. Sixty-eight intensive care units were not appropriate. The reason for this is, in 36 intensive care units, the person-incharge was not defined. Thirty-two intensive care units were specific intensive care units. Seventy intensive care units were eligible for the study. Of these, 35 intensive care units were excluded. The reasons for exclusion were 29 intensive care units did not agree to participate. Six intensive care units provided insufficient data. We worked with 45 intensive care units. In intensive care units, two patients had one nurse and one doctor worked for 24 hours. The study was conducted between March 1, 2018 and October 1, 2018.

\section{Participants}

Adult patients older than 18 years were included in this study. All patients with further life expectancy in the ICU were deemed eligible to participate. The inclusion criterion for this study was a diagnosis of sepsis and/or septic shock.

\section{Study data}

The prediction or confirmation of infection was performed through 24-hour bedside screening of the study participants. The mortality status of patients discharged from the ICU was determined by reaching the patients or their relatives by phone. The definition of infection was made according to the international sepsis guideline [17]. The presence of sepsis or septic shock was confirmed according to the standards set by the international sepsis datasheet; the definitions of these conditions were produced according to data published in the international sepsis datasheet [2]. The date of admission to the ICU, the infection source, the primary diagnosis, and the comorbidities present were recorded together with the patient's Acute Physiology and Chronic Health Evaluation (APACHE II) score. The Sequential Organ Failure Assessment (SOFA) score was recorded daily. Data on other comorbidities such as solid organ malignancy, diabetes mellitus, cerebrovascular disorders, chronic obstructive pulmonary disease (COPD), asthma, heart failure (New York Heart Association functional classes I-IV), coronary artery disease, liver failure, chronic renal failure (undergoing dialysis or serum creatinine $\geqslant 2 \mathrm{mg} / \mathrm{dL}$ ), immunosuppression (neutropenia $<500 \mathrm{~mm}^{3}$ ), hematologic malignancy, splenectomy, human immunodeficiency virus infection $\left(\mathrm{CD} 4<200 \mathrm{~mm}^{3}\right.$ ), receipt of chemotherapy or radiotherapy in the last six months prior to hospitalization in the ICU, receipt of corticosteroid treatment, and posttransplant status were also recorded.

\section{Definitions of data}

Definitions were made according to the Third International Consensus Definitions for Sepsis and Septic Shock (Sepsis-3). Sepsis was considered when an elevation of the Sepsis-related Organ Failure Assessment (qSOFA) score of two or more points occurred outside the ICU or an elevation of the SOFA score of two or more points occurred in the ICU in patients with suspected or proven infection. The qSOFA score is obtained by awarding one point per item when the following are positive: respiratory rate of at least 22 breaths/min, alteration in mental status, Glasgow Coma Scale score of less than 15 points, and systolic blood pressure of $100 \mathrm{mmHg}$ or less. When the SOFA score was two or more points, a preliminary diagnosis of sepsis was made after the exclusion of other probable causes of organ failure and the patient was admitted to the ICU. If the SOFA score manifested an elevation of two or more points, the diagnosis of sepsis was made. Septic shock was defined as a systolic blood pressure of less than $90 \mathrm{mmHg}$, a mean blood pressure of less than $65 \mathrm{mmHg}$ despite sufficient fluid loading, or a blood lactate level of more than $4 \mathrm{mmol} / \mathrm{L}(36 \mathrm{mg} / \mathrm{dL})$.

\section{Statistical analysis}

Quantitative data were expressed as mean (with 95\% confidence interval of mean) and standard deviation from the mean and were compared between groups using Student's t-Test. Categorical or qualitative data were expressed as frequency with corresponding percentages and were compared between survivors and non-survivors using Chi-square or Fisher's Exact Test. Level of significance was set at $5 \%$ or 0.05 and $p<0.05$ was considered significant. Statistical analysis was completed using the Statistical Package for the Social Sciences version 23.0 software program (IBM Corp., Armonk, NY, USA) and Stata software version 15.1 (Stata Corp LLC, College Station, TX, USA).

\section{Results}

A total of 138 ICUs were screened and data were collected from 45 ICUs (Figure 1). 


\section{Cureus}

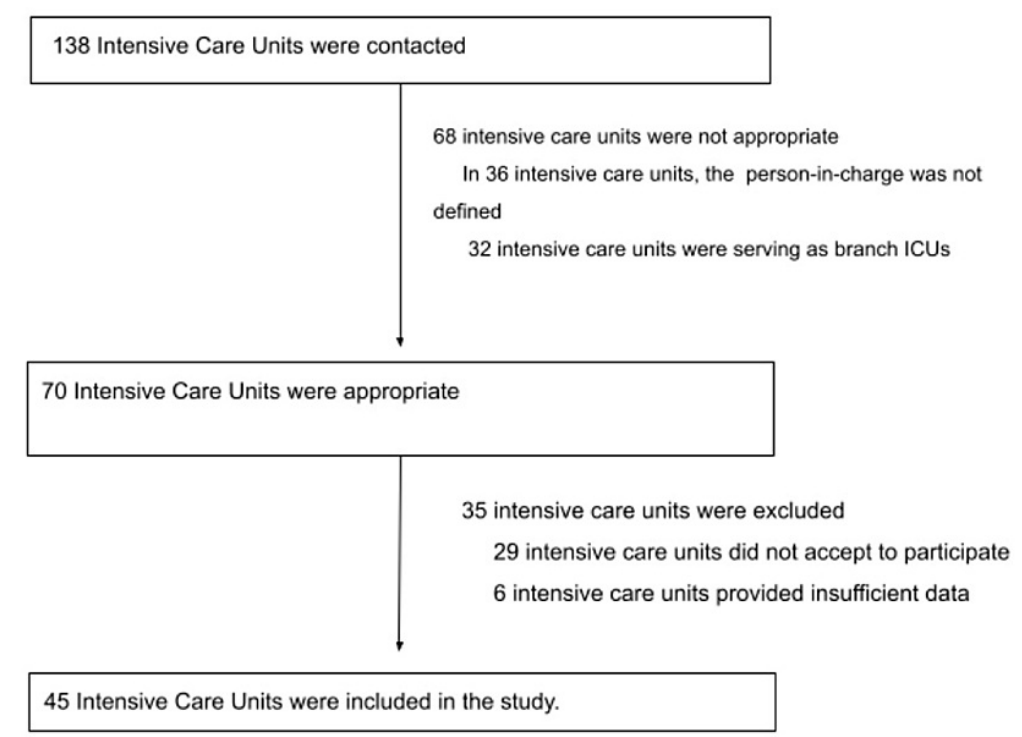

\section{FIGURE 1: Data collection from intensive care units}

\section{Variables}

Patient admission from university hospital, n (\%)

Training and research hospital where patients are admitted, $\mathrm{n}(\%)$

State hospital where patients are admitted, n (\%)

The number of hospital beds, $n(\%), \geq 500$

The number of hospital beds, $\mathrm{n}(\%),<500$

Age $\geq 65$, years

Gender Female, n (\%)

BMI $\left(\mathrm{kg} / \mathrm{m}^{2}\right)$ 18.5-24.9, n (\%)

BMI $\left(\mathrm{kg} / \mathrm{m}^{2}\right)$ 25-29.9, n (\%)

BMI $\left(\mathrm{kg} / \mathrm{m}^{2}\right)>30, \mathrm{n}(\%)$

Comorbidity, n (\%), COPD

Comorbidity, n (\%), HT

Comorbidity, n (\%), CRF

Other comorbid diseases, n (\%)

Immunosuppressed patient, $\mathrm{n}(\%)$

Pneumonia as a source of sepsis, $\mathrm{n}(\%)$

Abdominal as a source of sepsis, $n(\%)$

Urinary tract as a source of sepsis, $n(\%)$

\begin{tabular}{|c|c|c|c|}
\hline $\begin{array}{l}\text { All Patients ( } N= \\
642)\end{array}$ & $\begin{array}{l}\text { Survivors }(\mathrm{N}= \\
320)\end{array}$ & $\begin{array}{l}\text { Non-survivors }(\mathbf{N}= \\
322)\end{array}$ & $\mathbf{P}$ \\
\hline 172 (27\%) & $84(26 \%)$ & 88 (27\%) & \multirow{3}{*}{0.746} \\
\hline 316 (49\%) & 156 (49\%) & 160 (50\%) & \\
\hline 154 (24\%) & 80 (25\%) & 74 (23\%) & \\
\hline 325 (51) & 166 (26\%) & 159 (25\%) & \multirow{2}{*}{0.527} \\
\hline 317 (49) & 154 (24\%) & 163 (25\%) & \\
\hline 375 (58\%) & 189 (29\%) & $186(29 \%)$ & 0.244 \\
\hline 375 (59\%) & 189 (29\%) & $186(29 \%)$ & 0.749 \\
\hline 250 (39\%) & 119 (37\%) & 131 (41\%) & \multirow{3}{*}{0.496} \\
\hline 120 (19\%) & 65 (20\%) & 55 (17\%) & \\
\hline 272 (42\%) & 136 (43\%) & $136(42 \%)$ & \\
\hline 121 (19\%) & 59 (18\%) & 62 (19\%) & \multirow{4}{*}{0.212} \\
\hline 287 (45\%) & 132 (41\%) & $155(48 \%)$ & \\
\hline 187 (29\%) & 102 (32\%) & 85 (27\%) & \\
\hline 47 (7\%) & 27 (8\%) & 20 (6\%) & \\
\hline 134 (21\%) & 48 (15\%) & $86(27 \%)$ & 0.001 \\
\hline $311(48 \%)$ & 145 (45\%) & 166 (52\%) & \\
\hline 35 (6\%) & $18(6 \%)$ & 17 (5\%) & \\
\hline 58 (9\%) & 42 (13\%) & 16 (5\%) & 0.020 \\
\hline
\end{tabular}




\section{Cureus}

\begin{tabular}{|c|c|c|c|c|}
\hline Bacteremia as a source of sepsis, $n(\%)$ & $130(20 \%)$ & $55(17 \%)$ & $75(23 \%)$ & \\
\hline Sepsis source cannot be identified, n (\%) & $108(17 \%)$ & $60(19 \%)$ & $48(15 \%)$ & \\
\hline Medical intensive care, $\mathrm{n}(\%)$ & $223(35 \%)$ & $125(39 \%)$ & $98(30 \%)$ & \multirow{2}{*}{0.793} \\
\hline Surgical intensive care, $\mathrm{n}(\%)$ & $419(65 \%)$ & $195(61 \%)$ & $224(70 \%)$ & \\
\hline Number of single antibiotics empirically, $\mathrm{n}(\%)$ & $496(78 \%)$ & $261(81 \%)$ & $235(72 \%)$ & \multirow{2}{*}{0.034} \\
\hline Empirically double antibiotic count, n (\%) & $146(22 \%)$ & $59(19 \%)$ & $87(28 \%)$ & \\
\hline APACHE II score <17, n (\%) & $54(8.4 \%)$ & $33(10 \%)$ & $21(6 \%)$ & \multirow{2}{*}{0.084} \\
\hline APACHE II score >17, n (\%) & $588(91.6 \%)$ & $287(90 \%)$ & 301 (94\%) & \\
\hline Number of patients taken from the ward to intensive care unit, $n(\%)$ & $181(28 \%)$ & $85(27 \%)$ & $96(30 \%)$ & \multirow{3}{*}{0.584} \\
\hline $\begin{array}{l}\text { Number of patients admitted to intensive care from other intensive } \\
\text { care, } n(\%)\end{array}$ & $159(25 \%)$ & $84(26 \%)$ & $75(23 \%)$ & \\
\hline $\begin{array}{l}\text { Number of patients admitted to intensive care from the emergency } \\
\text { department, } n(\%)\end{array}$ & $302(47 \%)$ & $151(47 \%)$ & $151(47 \%)$ & \\
\hline Gram-positive microorganism causing sepsis, $\mathrm{n}(\%)$ & $83(13 \%)$ & $40(13 \%)$ & $43(13 \%)$ & \multirow{4}{*}{0.584} \\
\hline Gram-negative microorganism causing sepsis, n (\%) & $285(44 \%)$ & $151(47 \%)$ & $134(42 \%)$ & \\
\hline Number of culture negative sepsis, n (\%) & $130(20 \%)$ & $62(19 \%$ & $68(21 \%)$ & \\
\hline Other microorganisms that cause sepsis, $\mathrm{n}(\%)$ & $144(22 \%)$ & $67(21 \%)$ & $77(24 \%)$ & \\
\hline Number of septic episodes 1, n (\%) & $513(80 \%)$ & $243(76 \%)$ & $270(84 \%)$ & \multirow{2}{*}{0.012} \\
\hline Number of septic episodes $\geq 2, n$ (\%) & $129(20 \%)$ & 77 (24\%) & $52(14 \%)$ & \\
\hline
\end{tabular}

TABLE 1: Demographic and clinical characteristics of the patients

The three- and six-hour bundle protocol compliance rates were both 0\% (Table 2). 
Variables

Septic shock, n (\%)

Sepsis, $n(\%)$

The time to diagnosing sepsis, $n(\%) \leq 6$ hours

The time to diagnosing sepsis, $n(\%)>6$ hours

I used bolus fluid $30 \mathrm{ml} / \mathrm{kg}, \mathrm{n}(\%)$

I did not use bolus liquid $30 \mathrm{ml} / \mathrm{kg}, \mathrm{n}(\%)$

The amount of bolus fluid used $(\mathrm{ml})$, Mean \pm SD

The amount of culture taken in the first hour according to the sepsis bundle recommendation, $\mathrm{n}(\%)$

Cultures were not bundle-compliance in the first hour, $\mathrm{n}(\%)$

Antibiotics were administered in the first hour, $\mathrm{n}(\%)$

Antibiotics were not administered in the first hour, $\mathrm{n}(\%)$

First culture time, Median (IQR), min.

First antibiotic time, Median (IQR), min.

When was lactate measured first? Median (IQR), min.

When was the bolus fluid given? Median (IQR), min.

If MAP $<65 \mathrm{mmHg}$, when was vasopressor started? Median (IQR), min.

The time for second lactate measurement, Median (IQR), hours

One-hour bundle compliance

Three-hour bundle compliance

Six-hour bundle compliance

\begin{tabular}{|c|c|c|c|}
\hline $\begin{array}{l}\text { All Patients ( } N \\
=642)\end{array}$ & $\begin{array}{l}\text { Survivors ( } N \\
=320 \text { ) }\end{array}$ & $\begin{array}{l}\text { Non-survivors ( } N \\
=322)\end{array}$ & $\mathbf{P}$ \\
\hline 465 (72\%) & $213(67 \%)$ & 252 (78\%) & \multirow{2}{*}{0.001} \\
\hline 177 (28\%) & 107 (33\%) & 70 (22\%) & \\
\hline $384(60 \%)$ & $193(60 \%)$ & $191(59 \%)$ & \multirow{2}{*}{0.797} \\
\hline $258(40 \%)$ & $127(40 \%)$ & $131(41 \%)$ & \\
\hline 74 (12\%) & 40 (13\%) & 34 (11\%) & \multirow{2}{*}{0.461} \\
\hline 568 (88\%) & $280(77 \%)$ & $288(89 \%)$ & \\
\hline $1113 \pm 676$ & $1148 \pm 744$ & $1078 \pm 601$ & 0.503 \\
\hline 202 (31\%) & $180(56 \%)$ & $22(6 \%)$ & \multirow{2}{*}{0.001} \\
\hline 440 (68.5\%) & $140(44 \%)$ & 300 (94\%) & \\
\hline 324 (50\%) & 254 (79\%) & $70(22 \%)$ & \multirow{2}{*}{0.001} \\
\hline 318 (50\%) & $66(21 \%)$ & 252 (78\%) & \\
\hline $\begin{array}{l}24.0(12.0- \\
240.0)\end{array}$ & $\begin{array}{l}27.0(12.0- \\
240.0)\end{array}$ & $24.0(12.0-240.0)$ & 0.001 \\
\hline $\begin{array}{l}120.0(60.0- \\
300.0)\end{array}$ & $\begin{array}{l}90.0(27.0- \\
120.0)\end{array}$ & $\begin{array}{l}300.0(120.0- \\
600.0)\end{array}$ & 0.001 \\
\hline $\begin{array}{l}110.0(90.0- \\
150.0)\end{array}$ & $230(120-340)$ & $190(120-340)$ & 0.340 \\
\hline $\begin{array}{l}20.0(12.0- \\
34.0)\end{array}$ & $\begin{array}{l}23.0(12.0- \\
34.0)\end{array}$ & $19.0(12.0-34.0)$ & 0.529 \\
\hline $\begin{array}{l}40.0(20.0- \\
60.0)\end{array}$ & $\begin{array}{l}34.5(18.0- \\
59.5)\end{array}$ & $40.0(20.0-60.0)$ & 0.069 \\
\hline $\begin{array}{l}24.0(18.0- \\
24.0)\end{array}$ & $\begin{array}{l}24.0(26.0- \\
24.0)\end{array}$ & $24.0(18.0-24.0)$ & 0.709 \\
\hline $0(0 \%)$ & $0(0 \%)$ & $0(0 \%)$ & NS \\
\hline $0(0 \%)$ & $0(0 \%)$ & $0(0 \%)$ & NS \\
\hline $0(0 \%)$ & $0(0 \%)$ & 0 (0\%) & NS \\
\hline
\end{tabular}

TABLE 2: Bundle compliance of patients

The 2018 SSC one-hour bundle protocol compliance rate was also $0 \%$. The rate of obtaining an appropriate culture in the first three-hour bundle was $31 \%$, while the rate of using appropriate antibiotics at an appropriate time was $50 \%$. Additionally, the rate of initial administration of an appropriate fluid bolus was $12 \%$ and the mean fluid bolus volume was $1,113 \pm 676 \mathrm{~mL}$. Further, the initiation of a vasopressor drug if the mean blood pressure was less than $65 \mathrm{mmHg}$ presented a rate of $11.5 \%$, while the rate of second lactate measurement was $0 \%$. The rate of assessing at least two items among the parameters of central venous pressure (CVP) measurement, central venous oxygen saturation ( $\mathrm{ScvO}$ )2, cardiac ultrasonography, dynamic testing, and passive lower-extremity elevation testing - besides the vital signs, cardiopulmonary findings, capillary refilling, and cutaneous findings - to determine the volume and perfusion status of a patient was $0.3 \%$. The median number of days that a mechanical ventilator was used was 10 (interquartile range: $5-23$ days). The mortality rate due to sepsis in the intensive care unit was $22 \%$. The mortality rate due to septic shock in the intensive care unit was $78 \%$.

\section{Discussion}

In our study involving 45 ICUs, we determined that the one-hour bundle compliance rate was $0 \%$. Also, we found that the three- and six-hour bundle compliance rates were each $0 \%$. These results are quite low when compared to those recorded from both developing and developed countries $[5,18]$. In our study, the most 
significant deviation from compliance was seen with the absence of recurrent lactate measurements within the one- and six-hour bundles. In a similar study conducted in Asian countries with high- and middle-level incomes, those with low middle and middle-level incomes reported a rate of compliance with the six-hour resuscitation bundle of $6.9 \%$ and a mortality rate of 50\% [19]. In a study conducted in Bangladesh, which is a low-income country, the six-hour resuscitation bundle compliance rate was $0 \%$, with the hospital mortality rate being $49.2 \%$ [20]. In a multicenter study performed in Asia, the team reported a level of $7.6 \%$ bundle compliance. After the sepsis training was given to physicians, the bundle compliance rate was 37.5\% [18].

A study of developed and developing countries reported a total three-hour bundle compliance rate of $19 \%$. In this study, the highest three-hour bundle compliance was found in North America, with 29\%. Mortality is reduced with greater bundle protocol compliance and the highest six-hour compliance is in western Europe, found as $36 \%$ [5]. On the contrary, the lowest bundle compliance was found to be $26 \%$ in Africa and Central Asia. In large retrospective studies in the United States of America, it has been found that mortality decreases with bundle compliance [21-22].

Multicenter sepsis study was carried out in Turkey. In this study, sepsis bundle compliance is very low and mortality is high [5]. Among the ways to increase sepsis bundle compliance are education (meeting, bedside training, etc.) and increasing the standardization of sepsis treatment (predefined order sets, screening tools, sepsis teams) [23]. Alnababteh et al.'s 24/7 sepsis teams increased the sepsis bundle compliance from $10.7 \%$ to $36.9 \%$. They reduced the readmission rate from $5.9 \%$ to $4 \%$ and the mortality rate from $20 \%$ to $16 \%$ [24]. Moore et al. used the sepsis screening tool to increase the compliance rate of sepsis bundle and they increased the compliance rate [25]. Schramm et al. established a multidisciplinary response team and increased bundle compliance by $12.7 \%$ with weekly feedback [26].

The primary limitation of our study was that it was conducted only in tertiary ICUs and does not represent the conditions of other ICUs or hospital wards. There is therefore a need to conduct clinical trials in developing countries.

\section{Conclusions}

In conclusion, we found bundle compliance very low and mortality high in Turkey. Studies are needed to increase the compliance of sepsis bundle (effect of training, impact of the team, screening and feedback).

\section{Additional Information \\ Disclosures}

Human subjects: Consent was obtained or waived by all participants in this study. Katip Çelebi University Ethics Committee issued approval 77/2017. Approved by the Ethics Committee of Katip Çelebi University. Animal subjects: All authors have confirmed that this study did not involve animal subjects or tissue. Conflicts of interest: In compliance with the ICMJE uniform disclosure form, all authors declare the following: Payment/services info: All authors have declared that no financial support was received from any organization for the submitted work. Financial relationships: All authors have declared that they have no financial relationships at present or within the previous three years with any organizations that might have an interest in the submitted work. Other relationships: All authors have declared that there are no other relationships or activities that could appear to have influenced the submitted work.

\section{Acknowledgements}

Ömürhan Saraç, Betül Kozanhan, Onur Yiğitaslan, Ömer Ekinci, İclal Karaca, Seher Kır, Tuna Albayrak, Cengiz Mordeniz, Turgay Demir, Gülşen Özkan Tanriverdi, Roza Elif Balan, Andaç Dedeoğlu, Efraim Can Kaynak, Turan Evran, Murat Erdoğan, Burcu Acar Çinleti, Mustafa Özmen, Mustafa Yılmaz, Fatih Balcı, Bilge Çetin, Türkan Özer, Kardelen Akyüz, Canan Tiryaki, Engin Aktaş, Hüseyin Öz, Can Erdoğan, Andaç Dedeoğlu, Mehmet Akif Yazar, Seliman Çetinbulut, Berna Uyan, Saba Mukaddes Saygılı, Kaniye Aydın, Semih Aydemir, Zeliha Korkmaz Dişli, Didem Sözütek Akkoyun, Abuzer Avcı, Fulya Baturay, Selim Almaz and Nevcihan Şahutoğlu Bal.

\section{References}

1. Mayr FB, Yende S, Angus DC: Epidemiology of severe sepsis. Virulence. 2014, 5:4-11. 10.4161/viru.27372

2. Rhodes A, Evans LE, Alhazzani W, et al.: Surviving sepsis campaign: International Guidelines for Management of Sepsis and Septic Shock: 2016. Intensive Care Med. 2017, 43:304-377. 10.1007/s00134-0174683-6

3. Levy MM, Evans LE, Rhodes A: The surviving sepsis campaign bundle: 2018 update. Intensive Care Med. 2018, 44:925-928. 10.1007/s00134-018-5085-0

4. Evans L: A closer look at sepsis-associated mortality . JAMA Netw Open. 2019, 2:e187565. 10.1001/jamanetworkopen.2018.7565

5. Rhodes A, Phillips G, Beale R, et al.: The surviving sepsis campaign bundles and outcome: results from the International Multicentre Prevalence Study on Sepsis (the IMPreSS study). Intensive Care Med. 2015, 41:1620-1628. 10.1007/s00134-015-3906-y

6. Timsit JF, Ruppe E, Ferrer R: Focus on sepsis: new concepts and findings in sepsis care. Intensive Care Med. 
2018, 44:1997-1999. 10.1007/s00134-018-5406-3

7. WHO: Sepsis. (2020). Accessed: April 13, 2021: https://www.who.int/news-room/fact-sheets/detail/sepsis.

8. Rudd KE, Kissoon N, Limmathurotsakul D, et al.: The global burden of sepsis: barriers and potential solutions. Crit Care. 2018, 22:232. 10.1186/s13054-018-2157-Z

9. Ediboğlu Ö, Moçin ÖY, Özyılmaz E, et al.: Current statement of intensive care units in Turkey: data obtained from 67 Centers. Turk Thorac J. 2018, 19:209-215. 10.5152/TurkThoracJ.2018.170104

10. Guo A, Bowling JM, Bartram J, Kayser G: Water, sanitation, and hygiene in rural health-care facilities: a cross-sectional study in Ethiopia, Kenya, Mozambique, Rwanda, Uganda, and Zambia. Am J Trop Med Hyg. 2017, 97:1033-1042. 10.4269/ajtmh.17-0208

11. Rello J, Leblebicioglu H: Sepsis and septic shock in low-income and middle-income countries: need for a different paradigm. Int J Infect Dis. 2016, 48:120-122. 10.1016/j.ijid.2016.04.017

12. Dugani S, Veillard J, Kissoon N: Reducing the global burden of sepsis . CMAJ. 2017, 189:E2-E3. 10.1503/cmaj. 160798

13. WORLDBANK: data for upper middle income, Turkey. (2021). Accessed: April 13, 2021: https://data.worldbank.org/?locations=XT-TR.

14. Levy MM, Rhodes A, Phillips GS, et al.: Surviving sepsis campaign: association between performance metrics and outcomes in a 7.5-year study. Crit Care Med. 2015, 43:3-12. 10.1097/CCM.0000000000000723

15. Evans IVR, Phillips GS, Alpern ER, et al.: Association between the New York sepsis care mandate and inhospital mortality for pediatric sepsis. JAMA. 2018, 320:358-367. 10.1001/jama.2018.9071

16. Baykara N, Akalın H, Arslantaş MK, et al.: Epidemiology of sepsis in intensive care units in Turkey: a multicenter, point-prevalence study. Crit Care. 2018, 22:93. 10.1186/s13054-018-2013-1

17. Calandra $\mathrm{T}$, Cohen $\mathrm{J}$ : The international sepsis forum consensus conference on definitions of infection in the intensive care unit. Crit Care Med. 2005, 33:1538-1548. 10.1097/01.ccm.0000168253.91200.83

18. Memon JI, Rehmani RS, Alaithan AM, El Gammal A, Lone TM, Ghorab K, Abdulbasir A: Impact of 6-hour sepsis resuscitation bundle compliance on hospital mortality in a Saudi hospital. Crit Care Res Pract. 2012, 2012:273268. 10.1155/2012/273268

19. Phua J, Koh Y, Du B, et al.: Management of severe sepsis in patients admitted to Asian intensive care units: prospective cohort study. BMJ. 2011, 342:d3245. 10.1136/bmj.d3245

20. Faruq MO, Ahsan AA, Nazim Uddin M, et al.: Implementation of sepsis bundles in intensive care units of Bangladesh: a prospective observational study. Bangladesh Crit Care J. 2013, 1:8-17. 10.3329/bccj.v1i1.14359

21. Mouncey PR, Osborn TM, Power GS, et al.: Trial of early, goal-directed resuscitation for septic shock . N Engl J Med. 2015, 372:1301-1311. 10.1056/NEJMoa1500896

22. Kovacevic P, Dragic S, Kovacevic T, et al.: Impact of weekly case-based tele-education on quality of care in a limited resource medical intensive care unit. Crit Care. 2019, 23:220. 10.1186/s13054-019-2494-6

23. Damiani E, Donati A, Serafini G, et al.: Effect of performance improvement programs on compliance with sepsis bundles and mortality: a systematic review and meta-analysis of observational studies. PLoS One. 2015, 10:e0125827. 10.1371/journal.pone.0125827

24. Alnababteh MH, Huang SS, Ryan A, McGowan KM, Yohannes S: A multimodal sepsis quality-improvement initiative including 24/7 screening and a dedicated sepsis response team-reduced readmissions and mortality. Crit Care Explor. 2020, 2:e0251. 10.1097/CCE.0000000000000251

25. Moore LJ, Jones SL, Kreiner LA, et al.: Validation of a screening tool for the early identification of sepsis . J Trauma. 2009, 66:1539-1547. 10.1097/TA.0b013e3181a3ac4b

26. Schramm GE, Kashyap R, Mullon JJ, Gajic O, Afessa B: Septic shock: a multidisciplinary response team and weekly feedback to clinicians improve the process of care and mortality. Crit Care Med. 2011, 39:252-258. 10.1097/CCM.0b013e3181ffde08 